\title{
A Guided Inquiry Laboratory to Enhance Students' Understanding of the Law of Mechanical Energy Conservation
}

\author{
Dumcho Wangdi ${ }^{\mathrm{a}}$, Monamorn Precharattana ${ }^{\mathrm{a}}$ and Paisan Kanthang ${ }^{\mathrm{b}}$ \\ Corresponding Author: mprecharattana@ hotmail.co.th \\ anstitute for Innovative Learning, Mahidol University, Nakhon Pathom 73170, Thailand \\ ${ }^{b}$ Rajamangala University of Technology Phra Nakhon, Bangkok 10300, Thailand
}

Keywords: mechanical energy conservation, hands-on model, guided inquiry laboratory

\begin{abstract}
This study investigated tenth grade Bhutanese students' understanding of the law of mechanical energy conservation. A low-cost hands-on model developed using locally available materials designed as an integral part of a guided inquiry laboratory was used as intervention. A single-group pretest-posttest research design was employed. The instruments used to explore the students' conceptual understanding and views and attitudes were 13 two-tier multiple-choice items and 20 close-ended Likert-based items, respectively. The study also examined the students' views and attitudes toward a guided inquiry laboratory and the effectiveness of a hands-on model through a semi-structured interview protocol. The data was analysed by calculating the mean, standard deviation, and $t$-test. The paired-sample $t$-test indicated a significant enhancement of students' conceptual understanding due to the intervention of the guided inquiry laboratory from pretest $(\mathrm{M}=12.59, \mathrm{SD}=3.28)$ to posttest $[\mathrm{M}=21.39$, $\mathrm{SD}=3.07), t(99)=-52.14, \mathrm{p}<.005]$. The findings also indicated students having positive views and attitudes towards the guided inquiry laboratory and the developed hands-on model.
\end{abstract}

\section{Introduction}

Although the conservation of mechanical energy forms a fundamental part of any introductory physics (Hwu, 1980; Hassani, 2005; Santos, Soares, \& Tort, 2010; Li, 2012; Bambill, Benito, \& Garda, 2004), students are able to solve only the simple energy problems that do not involve the principles of energy conservation (Speltini \& Ure, 2002). The difficulty in learning this concept is often attributed to its abstract nature and unwarranted misconceptions held by students, possibly obtained because of inappropriate materials and pedagogies used in the classrooms. However, as scientists do, it is vital to breakdown abstract concepts and make them concrete and palatable for students to understand in a scientifically accurate way. Due to a helical structure of physics learning, untimely remedying of students' conceptual misunderstandings or vernacular misconceptions continuously confront them throughout the process of learning, making it difficult for them to transfer to their real-life situations.

The most common difficulty in understanding energy is the concept of its conservation (Swackhamer, 2005). It's passive meaning used synonymously with "saving" causes students to understand the energy conservation principle in an inaccurate way (Tatar \& Oktay, 2007). While students can nearly state the law of mechanical energy conservation, many still think that energy can be either created or destroyed (Swackhamer, 2005). Such ideas perceived by students are largely contradictory with scientific viewpoint.

The law of mechanical energy conservation states that energy can neither be created nor destroyed (Tatar \& Oktay, 2007) but can be transformed from one form to another. The total 
energy, both in the beginning and the end, remains the same no matter what kind of processes or events take place (Feynman, 1963). In Newtonian mechanics, it is implied that the sum of potential energy and kinetic energy is always constant in an isolated system (Wisniak, 2008; Santos et al., 2010).

Considering the existence of non-conserved forces (such as friction and gravity) to be negligible despite being pervasive, several studies were conducted regarding the law of mechanical energy conservation using various approaches. It was studied based on the Galilean principle of relativity (Santos et al., 2010), using projectile motion (Hwu, 1980), inclined experiment (Li, 2012), theory of inviscid fluid sheet (Shields \& Webster, 1989), conical pendulum (Bambill et al., 2004) and video analysis using Logger Pro (Bryan, 2010).

Speltini and Ure (2002) have conducted an exploratory research to study the principles, meaning, and examples of both conservation and non-conservation while Brook and Wells (1988) have documented the understanding of energy and energy conservation. Likewise research into students' ability to use energy conservation ideas in both written and practical problems (Driver \& Warrington, 1985), introduction of teaching sequence to assess concepts of energy conservation, use of pencil and paper tests (Mweene \& Mumb, 2012) and standardbased multiple choice to assess energy concepts, energy transfer and transformation and energy conservation (Herrmann-Abell \& DeBoer, 2011) and alternative conceptions of force and energy (Villarino, 2018) has been conducted.

Previous studies have revealed that the phenomenon of energy conservation, which is inevitable in nature, is practically challenging to demonstrate in the laboratory. While it is appropriate to include an experiment to demonstrate the phenomenon (Hwu, 1980) using ideal machines, in reality, cannot be made and do not exist (Feynman, 1963). In the real world, such forces like friction $(\mathrm{Li}, 2012)$ are always present. When doing such experiments, the variance of value is related to the presence of friction $(\mathrm{Li}, 2012)$.

In the Bhutanese context, the law of mechanical energy conservation is predominantly expressed using theoretical illustrations and imaginary explanation in the textbooks (Wangdi \& Tshomo, 2018). Very little information is available using the development of a guided inquiry laboratory in teaching the law of mechanical energy conservation. Therefore, this gap in the literature motivated the researchers to develop a guided inquiry laboratory with the following research questions:

i) What extent has the learning laboratory helped the students in understanding the law of mechanical energy conservation?

ii) What are the students' views and attitudes toward the developed learning laboratory?

iii) What extent has the developed hands-on model helped the students in understanding the law of mechanical energy conservation?

\section{Guided Inquiry Laboratory}

Inquiry underpins as an educational pedagogy across all science disciplines (Gordon et al., 2015). Despite emerging itself as an alternative to many other approaches, inquiry in science education is scarce (Gordon et al., 2015) and still does not contain clear and precise understanding of its constituents (Jackson \& Wenning, 2012). Because it covers a range of methods like illustrations, experimentations, investigations under the guidance of teacher and open investigations to explore students' own questions, defining inquiry has been difficult. In 
some contexts, it is used interchangeably with hands-on science and therefore, the need to clarify the terminology is strongly required (Tyler, 2007).

Generally, in inquiry-based science education, the students are engaged to develop knowledge, understand ideas and thinking processes used by the scientists in producing new knowledge (Abdi, 2014) and understanding the natural world (National Research Council, 1996). It is a pedagogical setting that depends less on textbooks as a main resource for information but more on a hands-on approach making students central to the learning episodes (Duran et al., 2004). National Research Council (2000) summarizes it succinctly to be understood in two ways:

i) The ability of the students to develop and conduct scientific examination and

ii) The understandings of how the scientists study the world.

Like scientists do, students investigate the things or events and propose based on the findings of their investigations. Guided inquiry is that form of teaching approach where the teacher provides the materials and the problem, and the student solve while teacher facilitates. In such classrooms the students and teachers work together collaboratively to meet the desired goals (Gordon et al., 2019; National Research Council, 1996). The students take a lead role in investigating the problem by formulating the hypothesis and framing some solutions. The data collection, interpretation and findings are also completed by the learners. The students are able to generalise their findings at the end of an activity (National Research Council, 1996; Nivalainen et al., 2013). There are four key stages in this approach: (a) posing with scientific questions; (b) formulating hypothesis; (c) data gathering and experimentation and (d) present findings and conclusion.

\section{Development of the Hands-on Model}

In this study, the main body of the hands-on model is made up of an acrylic ramp, which is attached to a metallic base. The acrylic was chosen because of its light weight, impact and water-resistance, durability, smoothness, and availability.

Five low-cost photogate sensors were embedded in the ramp of the acrylic inclined plane. These photogate sensors were created after assembling the cheap infrared and detectors available in the local market to be used for recording the time taken by the trolley. The photogate sensors were used since they are sensitive and precise in measuring the motion of an object (Galeriu, 2013). The trolley made from an acrylic board was used as an object in this study. A picket fence of length $(d) 0.04 \mathrm{~m}$ was attached beneath the trolley as a standard measure for duration of time $(t)$ the trolley used to move and pass through each photogate.

The ends of the photogate sensors were connected to the timer using a 23-pin VGA female and VGA female cable. The timer consisting of a microcontroller was devised using an open hardware called Arduino and open software called C+. It displays the time of a trolley when it passes through the arm of each of the photogate sensors by converting the voltage into analogue data. An AC/DC adapter with a voltage of $240 \mathrm{~V}$ was used to connect to the source of current. A wooden block was utilised below the ramp for easy adjustment of the height of the inclined plane as shown in Figure 1. 


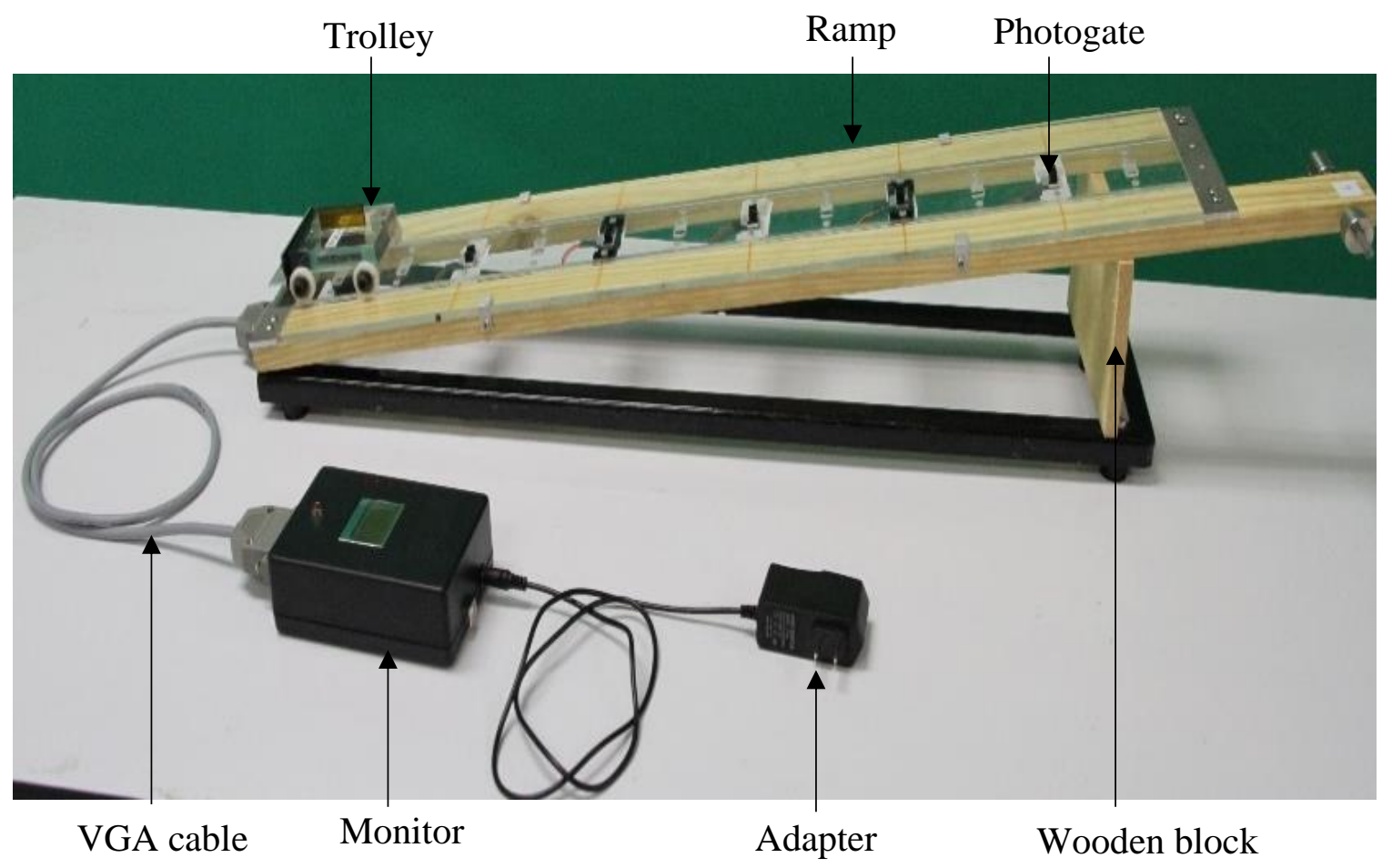

\section{Figure 1: The hands-on model}

\section{Working Mechanism of the Hands-on Model}

Connect the model to the current source. As the trolley passes through each sensor, the timer will display the time $t$ in milliseconds. The length of the picket fence beneath the trolley is the distance $d$. The mechanical energy is calculated using the relations of potential energy $\left(E_{p}\right)$ and kinetic energy $\left(E_{k}\right)$ as $E_{p}=m g h$ and $E_{k}=\frac{1}{2} m v^{2}$, respectively, where $m$ is the mass of a trolley, $g\left(9.8 \mathrm{~ms}^{-2}\right)$ is gravitational acceleration, and $h$ is the height of the center of mass of the trolley from outside the base. The height can be measured manually using a ruler from the upper side of the metallic base attached to the inclined plane. The instantaneous velocity can be calculated using $v=\frac{d}{t}$.

\section{Methodology}

\section{Implementation of the Proposed Guided Inquiry Laboratory}

In this study, a guided inquiry laboratory based on the framework of constructivism was developed. A simple hands-on model which formed an integral part in demonstrating the law of mechanical energy conservation was introduced. The guided inquiry laboratory that was designed for 120 minutes comprised of four main phases: posing scientific questions, formulating hypothesis, gathering data through experiment, and presenting findings and conclusion.

Before the intervention, the pretest that comprised of 13 two-tier multiple-choice items were administered for 20 minutes. The participants were then allowed to explore and demonstrate the law of mechanical energy conservation under the framework of a guided inquiry method for 80 minutes. The students were divided into a group of six to seven members each. 
The role of the teacher was to facilitate and direct the students towards achieving the objective of their experiment. Strictly based on the four phases, the teacher first posed a couple of scientific questions (posing scientific questions phase) and encouraged the children in formulating the hypothesis (formulating hypothesis phase). The set of questions was related to what they were supposed to find out and explain after doing the experiment using the handson model. The students were then directed to investigate their hypothesis in groups using the hands-on model, following the laboratory instructions provided to each group.

Through the experiment, each group gathered and analysed the data they obtained using the hands-on model and compared with the set of hypotheses they made during the first phase (gathering data through experiment phase). Each group then compiled their findings and presented to the entire class for discussion and confirmation (presenting findings and conclusion phase). Then, after the four phases of activities, the students were made to attend the posttest for 20 minutes which is the parallel two tiers multiple choice items used during the pretest.

Table 1 shows how the law of mechanical energy conservation was taught and what materials were used in each teaching phase of our proposed guided inquiry laboratory.

\section{Table 1: Our proposed guided inquiry laboratory}

\begin{tabular}{|c|c|c|}
\hline Teaching phases & Classroom activities & Material(s) used \\
\hline $\begin{array}{l}\text { Phase I } \\
\text { Posing scientific } \\
\text { questions }\end{array}$ & $\begin{array}{l}\text { a) What form of energy is there when the ball is at point A? } \\
\text { b) What kind of energy change takes place when it moves from } \\
\text { point A to point B? } \\
\text { c) How can you explain that the energy of this object is } \\
\text { conserved? } \\
\text { d) Can you define the law of mechanical energy } \\
\text { conservation? } \\
\text { - Students write down their answers in the student activity } \\
\text { sheet. }\end{array}$ & $\begin{array}{l}\text { Student activity } \\
\text { sheet }\end{array}$ \\
\hline $\begin{array}{l}\text { Phase II } \\
\text { Formulating } \\
\text { hypothesis }\end{array}$ & $\begin{array}{l}\text { - Students formulates hypotheses. Examples of expected } \\
\text { hypotheses by the students such as: } \\
\text { a) There is potential energy at point A because of its height. } \\
\text { b) The potential energy of an object at point A will start } \\
\text { changing to kinetic energy. At point B, instantly, the } \\
\text { potential energy of an object will completely change to a } \\
\text { kinetic energy. } \\
\text { c) Although there is a change of energy taking place as the } \\
\text { object moves from point A to point B, the total mechanical } \\
\text { energy remains same at each points. } \\
\text { d) It does not matter whether there is increase in kinetic } \\
\text { energy or decrease in potential energy, but the total } \\
\text { mechanical energy at all points remain same throughout. } \\
\text { - Teacher guides the students in setting the hypothesis. }\end{array}$ & $\begin{array}{l}\text { Student activity } \\
\text { sheet }\end{array}$ \\
\hline
\end{tabular}




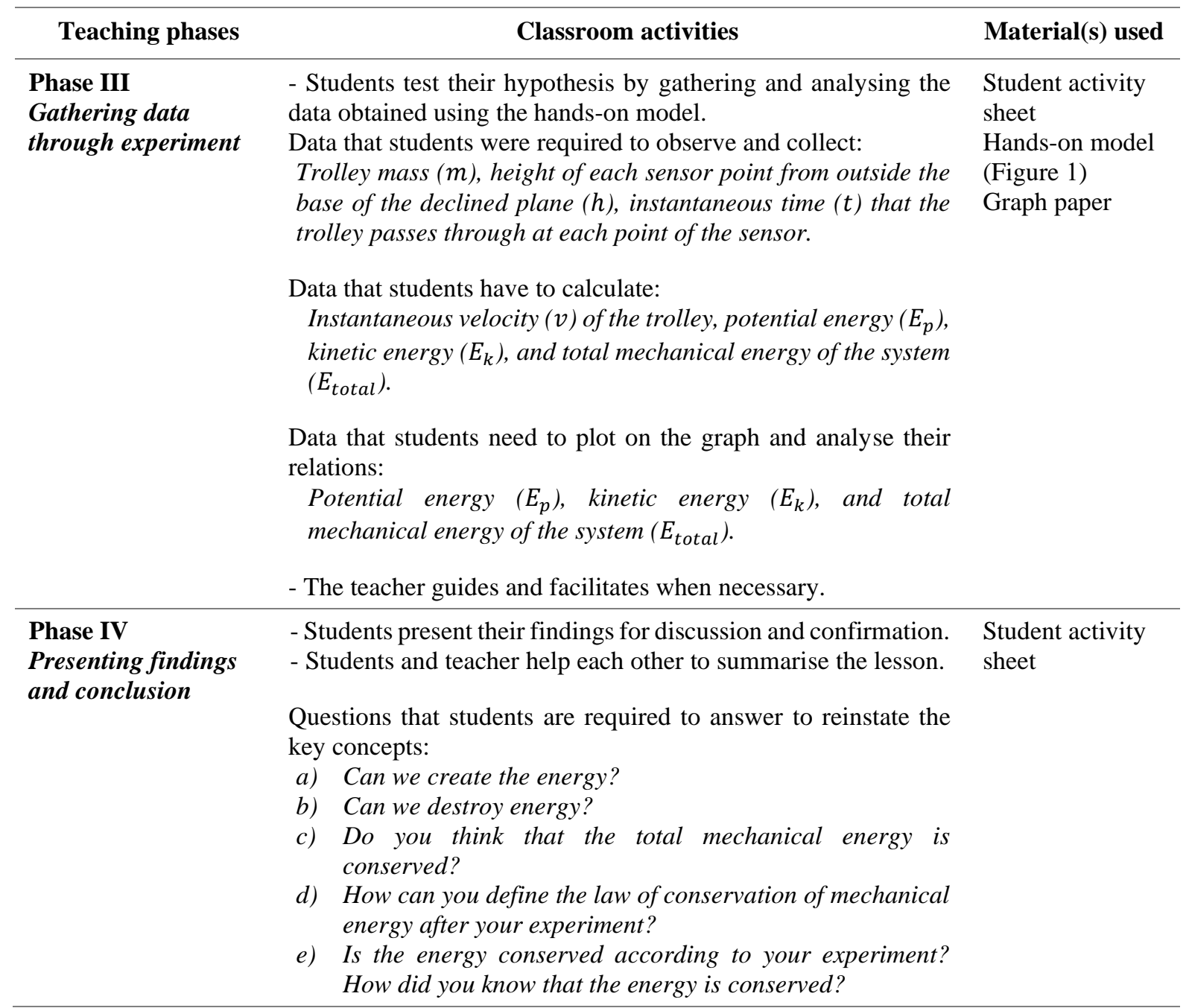

It is noted that for the purpose of this study which focused on grade ten students, the concept of energy conservation was made very simple. When the total mechanical energy (sum of potential energy and kinetic energy obtained by doing the activity) remains (approximately) the same, it was referred as energy being conserved.

\section{Research Design}

A single-group pretest-posttest design was undertaken in one of the middle secondary schools in the western part of Bhutan. 100 grade ten students were involved in this study. After the University Institutional Review Board granted the research approval, this study was conducted with further endorsement from the school principal, all the participants and their parents by signing the consent forms on voluntary basis.

\section{Instruments}

The data were collected using three research instruments, namely,

i) Conceptual Evaluation Test for Law of Mechanical Energy Conservation (CETMEC)

It comprised of 13 parallel two-tier multiple-choice items classified into three main constructs: energy conservation, energy created or destroyed, and energy is transferred or transformed according to the law of mechanical energy conservation. Ten items adapted from the American Association for Advancement of Science (AAAS Project, 2061) were modified into two-tiers multiple-choice format to align with the objective of this study. The remaining three items were self-created. The first tier examined students' understanding about the law of mechanical 
energy conservation, while the second tier evaluated their reasoning ability in justifying the choices made in the first tier.

In the first tier, there were three choices including True, False, and "I don't know". The second tier consisted of five possible reasons to support the choice the students made in the first tier but only one among these reasons was correct. Even in the second tier, "I don't know" was also included as an option in order to avoid the guess of students. This was considered to avoid errors or misunderstanding while analysing students' level of understanding. A sample of a two-tier item used in the CETMEC is shown in Figure 2.

\section{Directions:}

Read the statements carefully. There are TWO parts in each item. In the first part, you can Tick [ $\sqrt{ }$ ] whether the statements are TRUE, FALSE or DON'T KNOW based on your opinion. In the second part, you can Tick $[\sqrt{ }]$ for the reason that best supports your opinion in the first part.

1. Imagine that an object moves from point $A$ to $B$ which are at a same height in a horizontal direction. Suppose that there is no transfer of energy from ball to the track or from ball to the air, the total mechanical energy of a ball at point $B$ will remain same as the point $A$.
a) True
b) False
c) I don't know the answer

The reason for my answer is

a) Whether more or less, it will depend on the speed of object.

b) The energy is more because it went down the steep side of the track.

c) The energy will be less because it is used as it travels.

d) The total energy remains unchanged in a system.

e) I don't know the reason.

\section{Figure 2: A sample of two-tier item used in the CETMEC}

ii) Learners Attitude Questionnaire for Law of Mechanical Energy Conservation (LAQMEC)

It consisted of 20 Likert-based items covering six main constructs of a guided inquiry laboratory: topic of the lesson, teacher, classroom activities, learning method, hands-on model, and general classroom impression. A set of the questions used in the LAQMEC is shown in Figure 3. 


\begin{tabular}{|c|c|c|c|c|c|c|}
\hline \multicolumn{7}{|c|}{$\begin{array}{l}\text { Direction: } \\
\text { Read the statements carefully and TICK }[\sqrt{ }] \text { in the appropriate box which is given below the number. The } \\
\text { rating for the mumbers are given below: }\end{array}$} \\
\hline \multicolumn{2}{|r|}{ Acceptance Level } & \multicolumn{4}{|c|}{ Scores } & \\
\hline \multicolumn{2}{|r|}{ Strongly Agree $\quad(\mathrm{SA})$} & \multicolumn{4}{|c|}{5} & \\
\hline \multicolumn{2}{|r|}{$\begin{array}{ll}\text { Agree } & \text { (A) } \\
\text { Neither Arree nor disarree (N) }\end{array}$} & \multicolumn{4}{|c|}{4} & \\
\hline \multicolumn{2}{|r|}{ Neither Agree nor disagree (N) } & \multicolumn{4}{|c|}{3} & \\
\hline & Disagree & \multicolumn{4}{|c|}{2} & \\
\hline \multicolumn{2}{|r|}{ Strongly Disagree } & \multicolumn{4}{|c|}{1} & \\
\hline \multirow{2}{*}{\multicolumn{2}{|c|}{ Items }} & (SA) & (A) & (N) & (D) & (SD) \\
\hline & & & 4 & 3 & 2 & 1 \\
\hline 1 & The topic of the lesson was interesting & & & & & \\
\hline 2 & The lesson was suitable with the student level & & & & & \\
\hline 3 & The lesson was difficult to understand & & & & & \\
\hline 4 & The teacher helped to learn the lesson & & & & & \\
\hline 5 & The teacher respected the views of the students & & & & & \\
\hline 6 & The language teacher used was difficult to understand & & & & & \\
\hline 7 & The classroom activity made me actively involved in it & & & & & \\
\hline 8 & The activity helped me to use my head, hands and heart & & & & & \\
\hline 9 & The activity was difficult to understand the concept & & & & & \\
\hline 10 & The learning method was easy to follow & & & & & \\
\hline 11 & This method helped me share my knowledge and ideas & & & & & \\
\hline 12 & This method encouraged me to work in group & & & & & \\
\hline 13 & I would not prefer this learning method in the future & & & & & \\
\hline 14 & The hands-on model was user-friendly & & & & & \\
\hline 15 & The hands-on model was safe to use & & & & & \\
\hline 16 & The hands-on model was new and beneficial to me & & & & & \\
\hline 17 & The hands-on model helped to understand the concept better & & & & & \\
\hline 18 & I like the way the class was organized & & & & & \\
\hline 19 & I was satisfied with the class today & & & & & \\
\hline 20 & I felt happy after attending this class & & & & & \\
\hline
\end{tabular}

\section{Figure 3: A set of questions used in the LAQMEC}

\section{iii) Semi-structured interview protocol}

A semi-structured interview was administered to eight students on the basis of a random sampling method. All the dialogues were audio recorded and later transcribed into themes.

\section{Validity and Reliability}

Five national and international experts with experiences of teaching middle and higher secondary physics completed the validation of content. An index of item-objective congruence of 0.8 was obtained (Rovinelli \& Hambleton, 1977). The internal consistency (Cronbach's alpha) of 0.76 (Tavakol \& Dennick, 2011; Bland \& Altman, 1997) was established through a pilot study (Wangdi, Precharatanna, \& Kanthang, 2017) and later in subsequent studies (Wangdi \& Tshomo, 2018). The item difficulty index and the discrimination index of 0.7 and 0.47 were obtained respectively.

\section{Data Analysis}

A paired-sample $t$-test was employed to compare the means of the pretest and posttest. The CETMEC items were analyzed using students' level of understanding (Abraham et al., 1994). The students' responses were classified into four levels of understanding modified from Abraham, Williamson, and Westbrook (1994): sound understanding (SU), partial 
understanding with specific alternative conception (PUSAC), specific alternative conception (SAC), and no understanding (NU). When both the choice in the first tier and the reason in the second tier were correct, two points were awarded and labeled sound understanding. No points were given and classified no understanding when both the tiers were wrong. When only the first tier was correct, it was awarded with one point and grouped as partial understanding with specific alternative conceptions. Similarly, when only the second tier was correct, the responses were not given any score and labeled as specific alternative conceptions. It was considered this way because, the possibility of giving correct reasons without first having knowledge is not possible and therefore implies superficial learning. The responses from the eight interviewees were audio recorded and later transcribed using thematic coding (Braun \& Clarke, 2006).

\section{Results}

\section{Students' Understanding of the Law of Mechanical Energy Conservation}

A paired-sample $t$-test revealed a statistically significant difference between the mean score of pretest $(\mathrm{M}=12.59, \mathrm{SD}=3.28)$ and posttest $(\mathrm{M}=21.39, \mathrm{SD}=3.07)$ at $t(99)=-52.14, \mathrm{p}=.000$, $\alpha=.05$ (see Table 2). Since the $p$-value was found to be less than the alpha level $(\alpha=0.05)$, the null hypothesis was rejected. This indicated that the students' understandings were enhanced because of the treatment of the guided inquiry laboratory.

\section{Table 2: Paired-sample t-test}

\begin{tabular}{cccccc}
\hline Test & Mean & SD & t & df & Sig. (two-tailed) \\
\hline Pretest & 12.59 & 3.28 & & & \\
Posttest & 21.39 & 3.07 & -52.14 & 99 & .000 \\
\hline
\end{tabular}

To find out "to what extent has the guided inquiry laboratory enhanced the students' understanding on the law of mechanical energy conservation", the responses were categorised into four levels of understanding. Prior to the treatment, $24.92 \%$ students possessed SU, $34.46 \%$ PUSAC, $12.46 \%$ SAC, and $28.15 \%$ NU (refer Table 3 ).

However, after intervention, the percentage of SU rose to $75.38 \%$. The percentage of PUSAC, SAC, and NU decreased to 15.23, 6.08, and 3.31, respectively. These results indicated how the intervention of a guided inquiry laboratory enhanced the students' understanding on the law of mechanical energy conservation.

Table 3: Level of understanding for each item during pretest and posttest

\begin{tabular}{rllllllc}
\hline \multicolumn{6}{c}{ Proportion of students on each level of understanding (\%) } \\
Pretest & \multicolumn{5}{c}{ Posttest } \\
\hline SU & PUSAC & SAC & NU & SU & PUSAC & SAC & NU \\
24.92 & 34.46 & 12.46 & 28.15 & 75.38 & 15.23 & 6.08 & 3.31 \\
\hline${ }^{*}$ SU = sound understanding, PUSAC = partial understanding & with specific alternative conception, SAC = specific \\
alternative conceptions, $N U=$ no understanding &
\end{tabular}

The level of understanding for three constructs included in CETMEC was also analysed ( see Figure 4). It was found that the 'energy conservation' construct had the highest percentage of SU at $79.14 \%$ with the other two constructs at $72 \%$ and $75 \%$. The percentage of PUSAC was 
the highest in the 'energy is transferred or transformed' construct at $18 \%$, while NU was the least at $1.75 \%$ only.
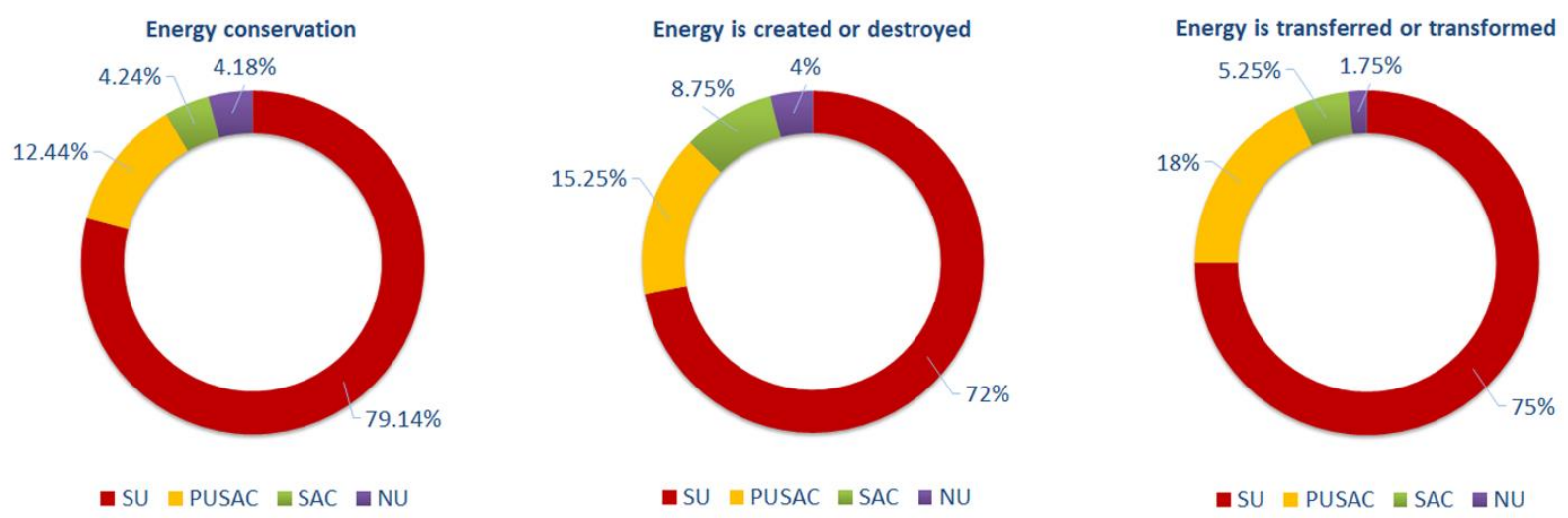

Figure 4: Level of understanding for each constructs (CETMEC)

\section{Students' Views and Attitudes toward the Guided Inquiry Laboratory}

The mean score of each item and construct included in LAQMEC were determined to examine the students' views and attitudes toward the guided inquiry laboratory and also to find the effectiveness of a hands-on model. The negatively stated items were reverse coded. The average mean score of all the constructs ranged from 4.62 to 4.99 as shown in Table 4 . The average of the overall means was 4.76 , which falls under the category of strong agreement. This indicated that the students liked the topic and the way the teacher taught; found the classroom activity interesting, the learning method suitable, and the hands-on model helpful to learn the concept; and felt satisfied after attending this class.

Table 4: Average mean scores of students' views and attitudes toward the guided inquiry laboratory

\begin{tabular}{lc}
\hline Constructs & Average mean scores \\
\hline Topic of the lesson & 4.62 \\
Teacher & 4.63 \\
Classroom activities & 4.73 \\
Learning method & 4.80 \\
Hands-on model & 4.99 \\
General classroom impression & 4.83 \\
\hline Average mean score of all constructs & $\mathbf{4 . 7 6}$ \\
\hline
\end{tabular}

\section{Effectiveness of a developed hands-on model}

The mean score for the hands-on model (4.99) was the highest among all the constructs. This score clearly indicated the students' strong agreement with the statement that the hands-on model was user-friendly, safe to use, beneficial, and effective in learning the law of mechanical energy conservation.

The interview transcripts validated the students' views and attitudes toward the guided inquiry laboratory and the effectiveness of the hands-on model when they said the following:

"It was new, interesting, and easy to use by us."

"Using the model, I could understand better, which I have not in theory." 
"By using the model, I gained a lot of knowledge, and it was helpful to understand the concepts easily."

"With the model, we can do the experiment again and again until it was clear."

Furthermore, the students agreed that the hands-on model was effective in understanding the law of mechanical energy when they said the following:

"Through the hands-on model, we can see and touch by ourselves, which helped to understand the concept more."

"The model helped me a lot in many ways. When we did the calculation, it proved that the total mechanical energy was always constant."

"Using the model can help me a lot in remembering things."

\section{Discussion}

This study investigated grade ten students' understanding of the law of mechanical energy conservation. It also examined the students' views and attitudes toward the developed guided inquiry laboratory and the effectiveness of a hands-on model. The statistically significant difference between the means of the posttest $(M=21.39 ; S D=3.07)$ and the pretest $(M=12.59$; $\mathrm{SD}=3.28$ ) indicated the enhancement of the students' understanding of the law of mechanical energy conservation because of the intervention of the guided inquiry laboratory. Such differences may also be attributed to the fact that the guided inquiry laboratory learning provides a range of activities for the students to observe, collect data, reflect, and critically analyse the events. In a teacher-student collaborated learning method like this, the teacher's role is limited to facilitator, while the students are guided to explore phenomena through inquiry.

Similar claims of guided inquiry supporting higher scientific achievements were also reported in the literature (Allen et al., 1986; Abdi, 2014; Duran et al., 2004; Chang \& Mao, 1998; Castro \& Morales, 2017). Allen, Barker, and Ramsden (1986) have established that a guided inquiry laboratory enhanced the students' achievement in chemistry as compared with the traditional cookbook learning. Abdi (2014) observed a significant statistical difference between the students taught using an inquiry method and a traditional approach. Duran, McArthur, and Van Hook (2004) found that the lecture-based physics introductory class converted to an inquirybased course to study energy, energy forms, and transfer mechanisms was more suitable in making physics concepts understandable to the students.

This study, which observed the highest percentage of understanding for the construct of energy conservation (79.14\%), is consistent with Mweene and Mumb (2012) and Tatar and Oktay (2007). Mweene and Mumb (2012) involved 90 premedical program students of Africa University to investigate the students' conceptual understanding of energy conservation and found that almost $90 \%$ of the students were able to state correctly the principle of energy conservation. However, the findings were in contrast with the study by Lee and Liu (2009), Brook and Wells (1988), Driver and Warrington (1985), and Herrmann-Abell and DeBoer (2011). Lee and Liu (2009), after the administration of 10 two-tier items to 2,688 middle school students, findings showed that the conservation of energy items needed higher knowledge integration levels when compared with understanding energy sources or energy forms and transformations. In the survey by Brook and Wells (1988), a majority of the students were observed having limited understanding on conservation. In their study, Driver and Warrington (1985) found that the concept of energy conservation was rarely used in analysing a problem. 
Herrmann-Abell and DeBoer (2011) revealed that the students had difficulties with items related to conservation and its application to a specific real world.

In this study, $15.23 \%$ of the students revealed partial understanding with specific alternative conception by responding with a correct choice in the first tier but incorrect reason in the second tier. Such learning happens when the students simply understand the basic and general facts without knowing the deep connections of the concept as a whole. Hence, this kind of learning is not meaningful, but rather, it is due to a rote learning or superficial learning (Bayrak, 2013). 6.08\% of the students showed specific alternative conception with the second tier correct and inaccurate choice in the first tier. In a real classroom situation, it may be rare to occur. The students who do not have any basic knowledge about the concepts, as stated in the first tier, would rather find it challenging to provide correct reasons in the second tier, which requires some analysis. The students responding with correct reasons can thus be ascribed to be the consequence of a blind guess.

The analysis of LAQMEC revealed the students possessing positive views and attitudes toward the guided inquiry laboratory. Such findings are consistent with Mattheis and Nakayama (1988); Karplus (1980); Bates (1980); Gibson and Chase (2002); Duran et al. (2004); Chatterjee et al., (2009) and Hofstein and Lunetta (2004). Mattheis and Nakayama (1988) found that laboratory-centered inquiry enhanced the performance of the middle secondary students. Karplus (1980) established that the inquiry learning led to improvement of the student laboratory skills. Gibson and Chase (2002) concluded that the students possessed higher interest and positive attitudes toward the science lesson taught with an inquiry-based approach. This is highly likely because inquiry involves asking questions and seeking knowledge (Sağlam \& Şahin, 2017). Similarly, Chatterjee, Williamson, McCann, and Peck (2009) suggested that perceiving the guided inquiry laboratory helped the students learn more compared with an open-inquiry laboratory. The interview transcripts of this study validated the students' possession of positive views and attitudes toward the guided inquiry laboratory. The consistent use of laboratory experience in science programs can improve the skills of handling the materials and equipment (Bates, 1980) and help the students understand abstract concepts using the scientific method of investigation (Hofstein \& Lunetta, 2004).

The mean score of the hands-on model, which was the highest of all other constructs, strongly indicated that the hands-on model was very effective in enhancing the students' understanding of the law of mechanical energy conservation. Using the hands-on model, the students were engaged in both hands-on and minds-on learning. These findings share similarity with those in the study of Stohr-Hunt (1996), Ateş and Eryilmaz (2011), Hussain and Akhtar (2013), Bigler and Hanegan (2011), and Holstermann et al., (2010). A study by Stohr-Hunt (1996) established that there was a significant difference in the students engaged in hands-on activities in terms of achieving higher science scores and understanding. Ateş and Eryilmaz (2011) concluded the hands-on to be effective in gaining higher achievement in physics. Hussain and Akhtar (2013) observed a significant statistical difference in science achievement in favor of experimental group instructed using a hands-on activity, while Bigler and Hanegan (2011) found an increased content knowledge in biotechnology after hands-on intervention. A study by Holstermann, Grube, and Bögeholz (2010) found the positive effects of hands-on experience in influencing students' interest. The effectiveness can also be attributed to the fact that handson science uses physical materials, allowing students firsthand experiences in scientific methodologies (Triona \& Klahr, 2007). The students involved in this study expressed that after using the hands-on model, they could retain the concepts in their mind for a longer period because they could "touch and feel." This opinion was in line with statements that hands-on 
activities let students touch, move and manipulate (Hull \& Roberts, 2003), and experience science to understand it better (Rutherford, 1993).

\section{Conclusion}

This study establishes the following three significant findings:

i) The guided inquiry laboratory enhanced the students' understanding of the law of mechanical energy conservation. This was evident from the statistically significant difference between the means of the pretest and posttest. The highest percentage of students having sound understanding at $75.38 \%$ consolidated this claim.

ii) The students' views and attitudes toward the guided inquiry laboratory were positive and affirmative. The overall mean score of the LAQMEC items was 4.76. The interview transcripts further validated this findings when the interviewees expressed affirmative responses such as The lesson was suitable and interesting; Now I can define the law of mechanical energy with examples and explanations of my own; The model helped me to understand the concept better; I am now more familiar and confident in doing some graphing works; and I was satisfied with the class today.

iii) The hands-on model was effective and suitable in enhancing the students' understanding of the law of mechanical energy conservation. There was a statistically significant difference between the means of the pretest and posttest because of the treatment of a guided inquiry laboratory, where the hands-on model formed the central part. The mean score of the hands-on model (4.99), which was the highest among all the constructs, revealed that the students have strongly agreed the hands-on model to be user-friendly, safe, effective, and beneficial in learning the concept. The interview responses further consolidated these findings.

The results of this study suggest that guided inquiry laboratory as an educational pedagogy can enhance students understanding of law of mechanical energy conservation. The use of handson model can be encouraged in our educational practices while teaching scientific concepts which have potential to create misconceptions for the students. Although the findings of this study are limited in generalisability, future researchers can incorporate other strategies in the process of teaching those concepts that are challenging for students.

\section{Acknowledgments}

This study was possible with the full scholarship assistance from Thailand International Development Cooperation Agency (TICA).

\section{References}

Abdi, A. (2014). The effect of inquiry-based learning method on students' academic achievement in science course. Universal Journal of Educational Research, 2(1), 37-41.

Abraham, M. R., Williamson, V. M., \& Westbrook, S. L. (1994). A cross-age study of the understanding of five chemistry concepts. Journal of Research in Science Teaching, 31(2), 147-165.

Allen, J., Barker, N., \& Ramsden, H. (1986). Guided inquiry laboratory. Journal of Chemical Education, 63(6), 533.

Ateş, Ö., \& Eryilmaz, A. (2011). Effectiveness of hands-on and minds-on activities on students' achievement and attitudes towards physics. Asia-Pacific Forum on Science. Learning and Teaching, 12(1), 1-22.

Bambill, H., Benito, M., \& Garda, G. (2004). Investigation of conservation laws using a conical pendulum. European Journal of Physics, 25(1), 31-35. 
Bates, G. (1980). The role of laboratory in secondary school science programs. In M. Rowe (Ed.), What Research Says to the Science Teacher (Vol. I). National Science Teachers Association.

Bayrak, B. (2013). Using two-tier test to identify primary students' conceptual understanding and alternative conceptions in acid base. Mevlana International Journal of Education, 19-26.

Bigler, A., \& Hanegan, N. (2011). Student content knowledge increases after participation in a hands-on biotechnology intervention. Journal of Science Education and Technology, 20(3), 246-257.

Bland, J., \& Altman, D. (1997). Statistics notes: Cronbach's alpha. BMJ, 314(7080), 570.

Braun, V., \& Clarke, V. (2006). Using thematic analysis in psychology. Qualitative Research in Psychology, 3(2), $77-101$.

Brook, A., \& Wells, P. (1988). Conserving the circus? An alternative approach to teaching and learning about energy. Physics Education, 23(2), 80-85.

Bryan, J. A. (2010). Investigating the conservation of mechanical energy using video analysis: Four cases. Physics Education, 45(1), 50.

Castro, J., \& Morales, M. (2017). "Yin" in a guided inquiry biology classroom - exploring student challenges and difficulties. Journal of Turkish Science Education, 14(4), 48-65.

Chatterjee, S., Williamson, V. M., McCann, K., \& Peck, M. L. (2009). Surveying students' attitudes and perceptions toward guided-inquiry and open-inquiry laboratories. Journal of Chemical Education, 86(12), 1427.

Chang, C., \& Mao, S. (1998). The effects of an inquiry based instructional method on Earth science students' achievement. Presented at the Annual Meeting of the National Association for Research in Science, San Diego, California.

Chou, C., Chan, P., \& Wu, H. (2007). Using a two-tier test to assess students' understanding and alternative conceptions of cyber copyright laws. British Journal of Educational Technology, 38(6), 1072-1084.

Driver, R., \& Warrington, L. (1985). Students' use of the principle of energy conservation in problem situations. Physics Education, 20, 171-176.

Duran, L. B., McArthur, J., \& Van Hook, S. (2004). Undergraduate students' perceptions of an inquiry-based physics course. Journal of Science Teacher Education, 15(2), 155-171.

Feynman, R. P. (1963). The Feynman Lectures on Physics, Volume I (Vol. 1). New York: Addison-Wesley.

Galeriu, C. (2013). An Arduino-Controlled Photogate. The Physics Teacher, 51(3), 156.

Gibson, H., \& Chase, C. (2002). Longitudinal impact of an inquiry-based science program on middle school students' attitudes toward science. Science Education, 86(5), 693-705.

Gordon, T., Sharma, M. D., Georgiou, H., \& Hill, M. (2015). Shifting towards inquiry-orientated learning in a high school outreach program. International Journal of Innovation in Science and Mathematics Education, 23(6), 63-74.

Gordon, T., Georgiou, H., Cornish, S., \& Sharma, M. (2019). Science in your pocket: Leaving high school students to their own 'devices' while designing an inquiry-based investigation. Teaching Science, 65(1), 17-26.

Hassani, S. (2005). Santa Claus and the conservation of energy. Physics Education, 40(6), 579.

Herrmann-Abell, C. F., \& DeBoer, G. E. (2011). Investigating students' understanding of energy transformation, energy transfer, and conservation of energy using standards-based assessment items. In Annual Meeting of the National Association of Researchers in Science Teaching, Orlando, FL.

Hofstein, A., \& Lunetta, V. (2004). The laboratory in science education: foundations for the twenty-first century. Science Education, 88(1), 28-54.

Hofstein, A., \& Mamlok-Naaman, R. (2007). The laboratory in science education: The state of the art. Chemistry Education Research and Practice, 8(2), 105-107.

Holstermann, N., Grube, D., \& Bögeholz, S. (2010). Hands-on activities and their influence on students' interest. Research in Science Education, 40(5), 743-757.

Hull, C., \& Roberts, D. (2003). Are hands-on activities more effective than traditional methods for eighth-grade math students? Bowling Green State University.

Hussain, M., \& Akhtar, M. (2013). Impact of hands-on activities on students' achievement in science: An experimental evidence from Pakistan. Middle East Journal of Scientific Research, 16(5), 626-632.

Hwu, Y. P. (1980). Conservation of mechanical energy. Physics Education, 15(5), 293.

Jackson, J., \& Wenning, C. J. (2012). Levels of inquiry: using inquiry spectrum learning sequences to teach science. Journal of Physics Teacher Education Online, 5(3), 11-20.

Karplus, R. (1980). Teaching for the development of reasoning. Research in Science Education, 10(1), 1-9.

Lee, H.-S., \& Liu, O. L. (2009). Assessing learning progression of energy concepts across middle school grades: The knowledge integration perspective. Science Education, 94(4), 665-688.

Li, C. (2012). Bowing effect on energy conservation in an incline experiment. Latin-American Journal of Physics Education, 6(1). 
Mattheis, F. E., \& Nakayama, G. (1988). Effects of a laboratory-centered inquiry program on laboratory skills, science process skills, and understanding of science knowledge in middle grades students. Reports- Research. 26.

Mweene, V., \& Mumb, F. (2012). Understanding energy conservation: Intersection between biological and everyday life contexts. In A. Zain Ahmed (Ed.), Energy Conservation. InTech.

National Research Council. (2000). Inquiry and the national science education standards: A guide for teaching and learning. The National Academies Press. https://doi.org/doi:10.17226/9596

National, Research Council. (1996). National science education standards. The National Academies Press. http://doi.org/10.5901/mjss.2013.v4n3p331

Nivalainen, V., Asikainen, M. A., \& Hirvonen, P. E. (2013). Open Guided Inquiry Laboratory in Physics Teacher Education. Journal of Science Teacher Education, 24(3), 449-474. https://doi.org:10.1007/s10972-012-9316$\mathrm{x}$

Rovinelli, R. J., \& Hambleton, R. K. (1977). On the use of content specialists in the assessment of criterionreferenced test item validity. Dutch Journal of Educational Research, Vol. 2, pp. 49-60.

Rutherford, F. J. (1993). Hands-on: A means to an end. 2061 Today, 3(1), 5.

Sağlam, M., \& Şahin, M. (2017). Inquiry-based professional development practices for science teachers. Journal of Turkish Science Education, 14(4), 66-76.

Santos, F. C., Soares, V., \& Tort, A. C. (2010). A note on the conservation of mechanical energy and the Galilean principle of relativity. European Journal of Physics, 31(4), 827-834.

Shields, J., \& Webster, W. (1989). Conservation of mechanical energy and circulation in the theory of inviscid fluid sheets. Journal of Engineering Mathematics, 23(1), 1-15.

Speltini, C., \& Ure, M. C. (2002). Conservation in physics teaching, history of science and in child development. Science \& Education, 11(5), 475-486.

Swackhamer, G. (2005). Cognitive resources for understanding energy. Retrieved from http://modeling.asu.edu/modeling/resources_10-03.pdf.

Tatar, E., \& Oktay, M. (2007). Students misunderstanding of energy conservation. International Journal of Environmental \& Science Education, 2(3), 79-81.

Tavakol, M., \& Dennick, R. (2011). Making sense of Cronbach's alpha. International Journal of Medical Education, 2, 53-55.

Triona, L. M., \& Klahr, D. (2007). Hands-on science: does it matter what students' hands are on? The Science Education Review, 6(4), 126-130.

Tyler, R. (2007). Re-imagining science education: Engaging students in-science for Australia's future Australian Council for Educational Research.

Villarino, G. N. B. (2018). College students' conceptual understanding of the concepts of force and energy: Comparisons with earlier studies. International Journal of Innovation in Science and Mathematics Education, 26(6), 22-61.

Wangdi, D., Precharatanna, M., \& Kanthang, P. (2017). Development of hands-on model embedded with guided inquiry laboratory to enhance students' understanding of law of mechanical energy conservation. Asia-Pacific Forum on Science Learning and Teaching, 18(2).

Wangdi, D., \& Tshomo, S. (2018). The effect of 5E learning cycle on students' understanding of the law of mechanical energy conservation. Rabsel - the CERD Educational Journal 19(1), 24-42.

Wisniak, J. (2008). Conservation of energy. Educación Química, 159-171. 